\title{
Bovine tuberculosis: clinical presentation and diagnosis
}

\begin{abstract}
Bovine tuberculosis (TB) is a chronic disease of animals caused by a bacterium called Mycobacterium bovis (M. bovis), which is closely related to the human bacterium and avian tuberculosis. Although cattle are considered true hosts of $M$. bovis, the disease has been reported in many domestic animals and undomesticated. Tuberculosis is usually a chronic debilitating disease in cattle, but it can occasionally be acute and rapidly progressive. TB is still common in less developed countries, and severe economic losses can occur from livestock deaths, chronic disease and trade restrictions. In some situations, this disease may also be a serious threat to endangered species. Bovine tuberculosis can be controlled by testand- slaughter or test-and-segregation methods. Affected herds are re-tested periodically to eliminate cattle that may shed the organism; the tuberculin test is generally used.
\end{abstract}

Keywords: bovine tuberculosis, mycobacterium bovis, domestic animals, segregation methods, zoonosis
Volume 3 Issue 2 - 2016

\author{
Aboukhassib H,' Haraji M,', Bouslikhane M, ${ }^{3}$ \\ Bitar $A^{\prime}$ \\ 'Nutrition and development of natural resources, Biochemistry \\ Laboratory, Morocco \\ ${ }^{2}$ Biochemistry and Nutrition, Laboratory of Biotechnology, \\ Morocco \\ ${ }^{3}$ Department of Pathology and animal health, agricultural and \\ veterinary institute Hassan II, Morocco
}

Correspondence: Haraji M, Biochemistry and Nutrition, Laboratory of Biotechnology, Faculty of Sciences of El Jadida, Morocco,Tel 0021266|877745, Email m.haraji@hotmail.com

Received: October 25, 2016 | Published: December 05, 2016

\section{Introduction}

Bovine tuberculosis is prevalent in animals of many developing countries whereas surveillance and control activities are often inadequate or unavailable; it is also a major zoonosis, mainly involving farm workers on dairy farms and the consumption of contaminated dairy products.

Zoonotic TB can also be considered a socio-economic disease; it has a negative impact on livestock production in developing countries through reduced production efficiency, carcass or organ condemnation and restriction of international trade. ${ }^{1}$

Although milk is considered as the main route for the transmission of BTB from cattle to human beings, Non-pasteurized milk is by far the most probable vehicle for the transmission of pathogenic mycobacteria. ${ }^{2}$ An estimated $32 \%$ of the world's population, or 1.86 billion people, are infected with Mycobacterium tuberculosis ${ }^{3}$ and more than eight million new cases of tuberculosis disease (TB) occur each year. ${ }^{4}$ Infections caused by Mycobacterium bovis are being increasingly documented as being the cause of epidemic nosocomial bursts in Paris. ${ }^{5}$

Polymerase chain reaction (PCR) is a sensitive and fast diagnostic tool that can be used to detect the agent in clinical samples in 48 $\mathrm{h}$, but the presence of inhibitors in samples can interfere with its performance. ${ }^{6,7}$ Tuberculosis profited from several major advances in immunopathology, diagnosis, treatment and vaccination. This pro-gress will be soon applied to improve the diagnosis (speed and reliability) and to shorten the treatment of tuberculosis. ${ }^{8,9}$

Many countries around the world perform the control or eradication of BTB by their official control of infectious diseases, based on testand-slaughter policy. Additional diagnostic tests are needed to make a quick diagnosis of the disease and develop vaccines in order to prevent bovine tuberculosis.

\section{Transmission}

Animals transmit infection to each other through ingestion of urine, faeces and lymph, wound discharge, infected milk along with food and water. TB elimination programs in domesticated herds together with milk pasteurization have successfully reduced the incidence rate of TB caused by M. bovis among cattle and humans alike in developed countries. ${ }^{10}$

Transmission could have been by aerosols or contamination of fodder due to indiscriminate spitting. Milk and meat are one of the most important links between bovine tuberculosis and human beings especially children. ${ }^{11,12} M$. bovis infection in humans can occur through inhalation of infectious droplets from a live or slaughtered animal or by consumption of unpasteurized dairy or meat products from infected animals. ${ }^{13,14}$ Vertical transmission can also occur in infected females. The uterus may serve as a portal for foetal infection and surviving calves commonly develop liver and spleen lesions. ${ }^{15}$ People working in animal husbandry, slaughterhouse workers, veterinarians, and people in close contact with possibly-infected animals are at a higher risk for M. bovis infection. ${ }^{16}$

\section{Pathogenesis}

The genus Mycobacterium is the unique genus of the family Mycobacteriaceae, order Actinomycetales, class Actinomycetes. M. bovis is one of the members of M. tuberculosis complex. Current taxonomy recognizes 8 members in this group i.e., M. tuberculosis, M. bovis, M. bovis BCG, M. caprae, M. africanum, M. pinnipedii, M. microti and M. Cannettii. ${ }^{17-20}$ M. bovis is an obligate intracellular pathogen; experimental studies have shown that it can survive under specific conditions. $M$. bovis can survive in faeces, blood, and urine from 150 to 332 days at 12 to $24^{\circ} \mathrm{C}$, when shielded from direct sunlight, particularly in cold, dark and moist conditions. The genome contains approximately 4000 genes, encoding different properties, potential virulence factors and antigens ${ }^{21}$ (Table 1). 
Table I Members of the mycobacterium tuberculosis complex and hosts

\begin{tabular}{lll}
\hline \multicolumn{1}{c}{ Members } & Main hosts \\
\cline { 2 - 3 } & M. tuberculosis & Human TB \\
M. bovis, M. bovis BCG & Cattle and human TB \\
$\begin{array}{lll}\text { M. tuberculosis } \\
\text { complex }\end{array}$ & $\begin{array}{ll}\text { M. canettii } \\
\text { M. microti }\end{array}$ & Human TB in Africa \\
M. caprae & Human TB \\
M. pinnipedii & TB in small rodents \\
\hline
\end{tabular}

\section{Diagnosis}

The global prevalence of human TB caused by M. bovis was estimated to be $3.1 \%$ of all human TB cases worldwide, accounting for $2.1 \%$ and $9.4 \%$ of pulmonary and extra pulmonary TB cases, respectively. ${ }^{22}$

To identify cattle infected with $M$. bovis, the intradermal tuberculin test is usually performed, which is based on the inoculation of $M$. Bovis antigens called purified protein derivative (PPD). Although the tuberculin skin test is highly sensitive and specific, it requires $48-72 \mathrm{~h}$ to process, and veterinarians must be specially trained to perform the assay.

The culture of milk samples is another approach to the detection of $M$. bovis, but while it provides acceptable sensitivity and specificity it is labor-intensive, with up to 6 weeks required to detect positive specimens. ${ }^{23}$ Identification of $M$. bovis in raw milk and tissue samples of domestic calves and goats from the West Bank is an important finding with economic and public health consequences.

In diagnosis of mycobacterial infections, culture is still considered the international gold standard. ${ }^{22}$ However, due to dysgenic and slow growth characteristics, the identification of $M$. bovis by culture and biochemical methods is cumbersome and time consuming. ${ }^{24}$ Furthermore, application of molecular techniques is expensive as it demands availability of adequate laboratory resources and trained personnel.

Lesions in cattle are most often found in organs rich in reticuloendothelial tissue, particularly the lungs and associated lymph nodes. ${ }^{25}$ Lesions are most commonly present in the lower respiratory tract, however the upper respiratory tract and its associated tissues also displays disease in many cases (Figure 1) (Figure 2).

Bovine tuberculosis (BTB) is a disease characterized by formation of granulomatous nodules called tubercles whose locations depend largely on the route of infection. In calves, it is usually transmitted by ingestion and lesions involve the mesenteric lymph nodes Figure 3 with possible spread to other organs. In older cattle, infection is usually by the respiratory tract with lesions in the lung and dependent lymph nodes. ${ }^{26}$

The necropsy procedure performed after slaughtering of animals allows for the detection of gross lesions suggestive of BTB, even in apparently healthy cattle. Veterinary inspection is established as a routine procedure in most of the slaughterhouses in developing countries. The detection of infected animals is mainly restricted to the routine slaughterhouse inspection. ${ }^{27}$ In cattle, tubercles are found in the lymph nodes, particularly those of the head Figure 4 and thorax. They are also common in the lung Figure 1, spleen, liver, heart Figure 5, kidney Figure 6 and the surfaces of body cavities. In disseminated cases, multiple small granulomas may be found in numerous organs. Lesions are sometimes found on the female genitalia, but are rare on the male genitalia.

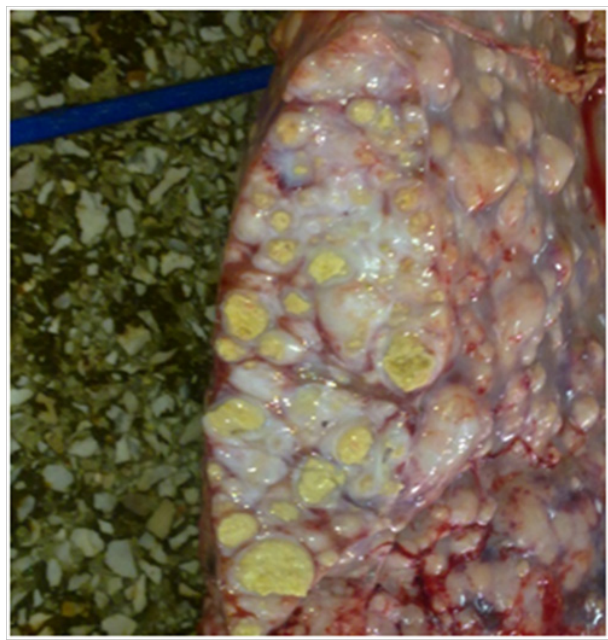

Figure I Lung from a tuberculous cow showing calcified granulomas.

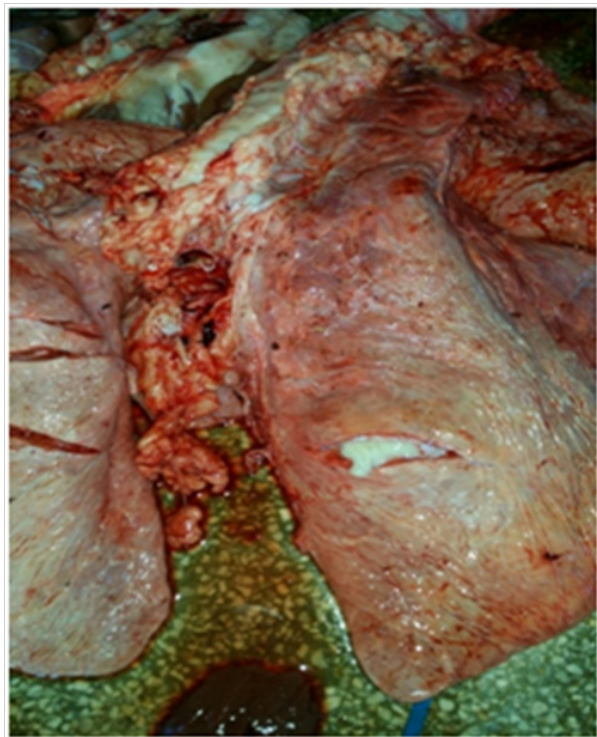

Figure 2 Lung lymph node from a tuberculous cow.

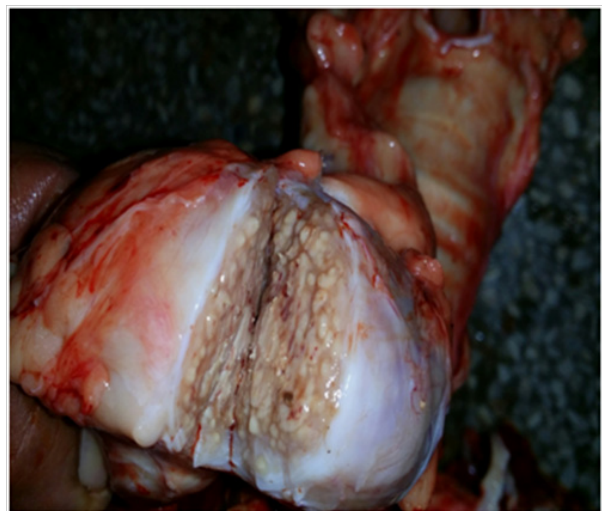

Figure 3 Lung lymph node from a tuberculous cow. 


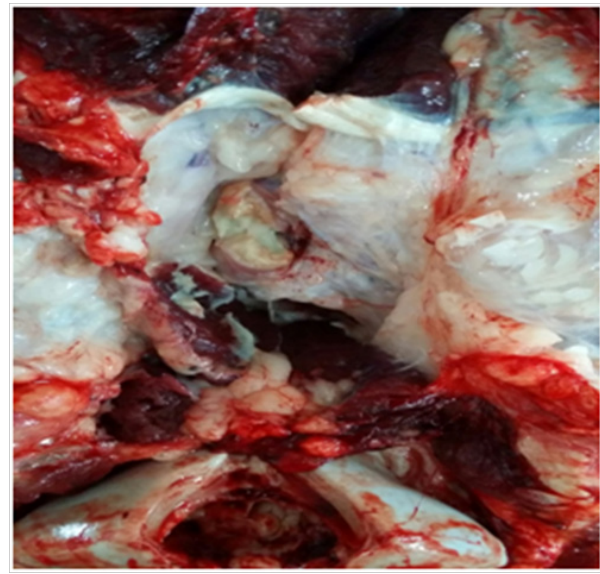

Figure 4 Head lymph node from a tuberculous cow.

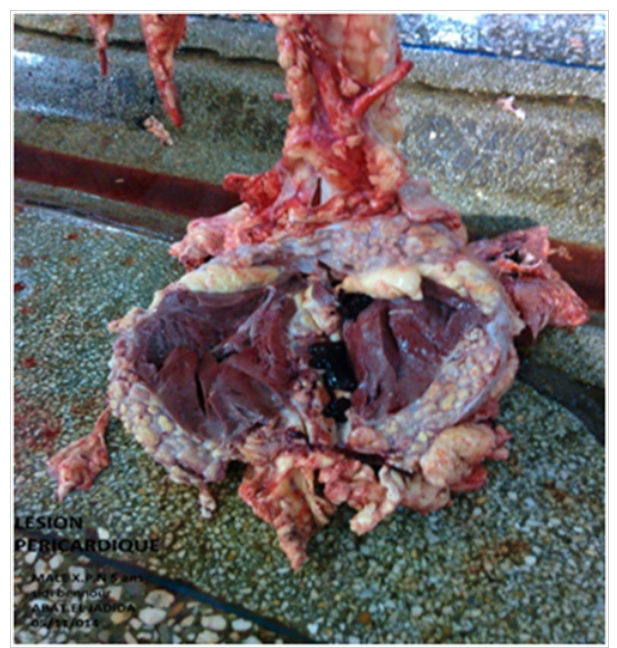

Figure 5 Cardiac lymph node from a tuberculous cow.

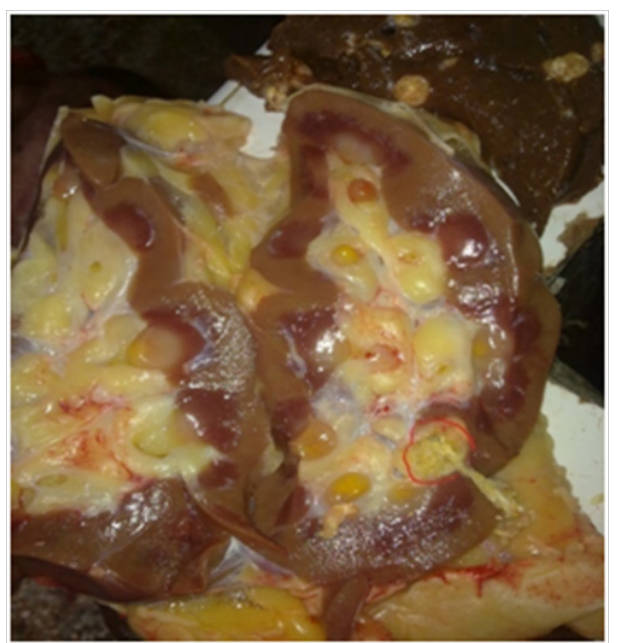

Figure 6 Kidney lymph node from a tuberculous cow.

A definitive diagnosis is still established by the isolation and identification of the etiological agent (M. bovis) from lymph nodes or lungs, obtained during necropsy or at slaughter, using a combination of traditional culture and biochemical methods, which is considered the "gold standard method". ${ }^{28}$ These methods are laborious, unreliable and time-consuming; it may take more than 90days to grow the microorganism, and an additional 2 weeks for biochemical identification. Molecular methods, especially the polymerase chain reaction (PCR) assay, are the most promising. However, the success of the PCR assay depends on the availability of intact and impurityfree DNA. ${ }^{29}$

\section{Acknowledgements}

None.

\section{Conflict of interest}

The author declares no conflict of interest.

\section{References}

1. Radostits OM, Gay CC, Blood DC, et al. Veterinary medicine: a text book of the disease of cattle, sheep, pigs, goats and horses. London: WB Saunders; 2007.

2. Regassa A, Medhin G, Ameni G. Bovine tuberculosis is more prevalent in cattle owned by farmers with active tuberculosis in central Ethiopia. Vet J. 2008;178(1):119-125.

3. Dye C, Scheele S, Dolin P, et al. Consensus statement. Global burden of tuberculosis: estimated incidence, prevalence, and mortality by country. WHO Global Surveillance and Monitoring Project. JAMA. 1999;282(7):677-686.

4. World Health Organization (WHO). Global tuberculosis control: WHO report. Geneva; 2011.

5. Bouvet E, Casalino E, Mendoza Sassi S, et al. A nosocomial outbreak of multidrug-resistant Mycobacterium bovis among HIV infected patients. A case-control study. AIDS. 1993;7(11):1453-1460.

6. Haddad N, Masselot M, Durand B. Molecular differentiation of Mycobacterium bovis isolates. Review of main techiques and applications. Res Vet Sci. 2004;76(1):1-18.

7. Singh SK, Verma R, Shah DH. Molecular finger printing of clinical isolates of Mycobacterium bovis and Mycobacterium tuberculosis from India by restriction fragment lenght polymorphism (RFLP). J Vet Sci. 2004;5(4):331-335.

8. Bergmann JS, Fish G, Woods GL. Evaluation of the BBL MGIT (Mycobacterial growth indicator tube) AST SIRE system for anti mycobacterial susceptibility testing of mycobacterium tuberculosis to4primary antituberculous drugs. Arch Pathol Lab Med. 2000;124(1):8286.

9. Brady M, Coronel J, Gilman R, et al. The MODS method for diagnosis of tuberculosis and multi-drug resistant tuberculosis. J Vis Exp. $2008 ; 17: 845$.

10. Taylor GM, Worth DR, Palmer S, et al. Rapid detection of Mycobacterium bovis DNA in cattle lymph nodes with visible lesions using PCR. BMC Vet Res. 2007;3:12.

11. Leite CQ, Anno IS, Leite SR, et al. Isolation and identification of mycobacterium from livestock specimens and milk obtained in Brazil. Mem Inst Oswaldo Cruz. 2003;98:319-23.

12. Cosivi O, Grange JM, Daborn CJ, et al. Zoonotic tuberculosis due to Mycobacterium bovis in developing countries. Emerg Infect Dise. 1998;4(1):59-70.

13. Grange JM. Mycobacterium bovis infection in human beings. Tuberculosis (Edinb). 2001;81(1-2):71-77.

14. LoBue P. Public health significance of Mycobacterium bovis. In: Thoen C, Steele J, editors. Mycobacterium bovis infection in animals and humans. 2nd ed. USA: Blackwell Publishing Press; 2006. p. 6-12. 
15. Biberstein EL, Hirsh DC. Mycobacterium species: the agents of animal tuberculosis. In: Hirsh DC, Zee YC, editors. Veterinary Microbiology. USA: Blackwell Science Press; 1999. p. 158-164.

16. Cousins DV, Dawson DJ. Tuberculosis due to Mycobacterium bovis in the Australian population: cases recorded during 1970-1994. Int J Tuberc Lung Dis. 1999;3(8):715-721.

17. Wayne LG, Kubica GP. The mycobacteria. In: Sneath PHA, Holt JG, editors. Bergey's manual of systematic bacteriology. USA: Williams and Wilkins; 1986. 2:1435-1445.

18. Van Soolingen D, Hoogenboezem T, de Haas PEW, et al. A novel pathogenic taxon of the Mycobacterium tuberculosis complex, canetti:characterization of an exceptional isolate from Africa. Int J Syst Bacteriol. 1997;47(4):1236-1245.

19. Cousins D, Williams S, Liébana E, et al. Evaluation of four DNA typing techniques in epidemiological investigations of bovine tuberculosis. $J$ Clin Microbiol. 1998;36(1) :168-178.

20. Aranaz A, Cousins D, Mateos A, et al. Elevation of Mycobacterium tuberculosis subsp. Caprae Aranaz et al. 1999 to species rank as Mycobacterium caprae comb. nov., sp. nov. Int J Syst Evol Microbiol. 2003;53(Pt 6):1785-1789.

21. Hewinson RG, Vordermeier HM, Smith NH, et al. Recent advances in our knowledge of Mycobacterium bovis: a feeling for the organism. Vet Microbiol. 2006;112(2-4):127-139
22. Ayele WY, Neill SD, Zinsstag J, et al. Bovine tuberculosis: an old disease but a new threat to Africa. Int J Tuberc Lung Dis. 2004;8(8):924-937.

23. Zumárraga JZ, Meikle V, Bernardelli A, et al. Use of touch-down polymerase chain reaction to enhance the sensitivity of Mycobacterium bovis detection. J Vet Diagn Invest. 2005;17(3):232-238.

24. Araujo CP, Leite CQ, Prince KA, et al. Mycobacterium bovis identification by a molecular method from post-mortem inspected cattle obtained in abattoirs of MatoGrosso do Sul, Brazil. Mem Inst Oswaldo Cruz. 2005;100(7):749-752.

25. Rodgers JD, Connery NL, McNair J, et al. Experimental exposure of cattle to a precise aerosolised challenge of Mycobacterium bovis:a novel model to study bovine tuberculosis. Tuberculosis (Edinb). 2007;87(5):405-414.

26. Carter GR, Changappa MM. Microbial disease. A veterinary guide to laboratory diagnosis, Lomastats. 1993. p. 123-128.

27. Corner LA. Post mortem diagnosis of Mycobacterium bovis infection in cattle. Vet Microbiol. 1994;40(1-2):53-63.

28. OIE. World Organisation for Animal Health-Bovine Tuberculosis. 2009.

29. Carvalho RCT, Furlanetto LV, Maruyama FH, et al. Evaluation of the efficiency of nested q-PCR in the detection of Mycobacterium tuberculosis complex directly from tuberculosis-suspected lesions in post-mortem macroscopic inspections of bovine carcasses slaughtered in the state of Mato Grosso, Brazil. Meat Sci. 2015;106:11-15. 